\title{
Anxiety Scale
}

National Cancer Institute

\section{Source}

National Cancer Institute. Anxiety Scale. NCI Thesaurus. Code C121276.

A rating scale included in the Behavior Assessment System for Children that measures

the tendency of the subject to be nervous, fearful, or worried about real or imagined problems. 